\title{
Evaluation of Salivary Antioxidant Enzymes among Smokers and Nonsmokers
}

Tajinder Kaur Saggu, KMK Masthan, Mahesh Pundaleek Dudanakar, Shams UI Nisa, Shankargouda Patil

\begin{abstract}
Background: Cigarette smoke contains various oxygen-free radicals which are considered as the main causes of damage to biomolecules when exposed to cigarette smoke. Saliva is the first biological fluid that encounters inhaled cigarette smoke (CS) and has an antioxidant defense system able to counter toxic activities of free radical species. So, the aim of this study was to compare the levels of superoxide dismutase (SOD) and glutathione peroxidase (GSH-Px) in saliva of smokers and nonsmokers.
\end{abstract}

Materials and methods: Unstimulated saliva of 200 males (100 smokers and 100 nonsmokers) was collected. The saliva was centrifuged and the activity of salivary superoxide dismutase and glutathione peroxidase was measured according to a specific assay.

Results: The mean value of superoxide dismutase activity was significantly higher in the smoking group than in the nonsmoker group, while the levels of GSH-Px activity was significantly higher in the nonsmoking group than in the smoking group.

Conclusion: Cigarette smoke leads to an alteration in salivary antioxidant activity. Evaluating the variations in the level of antioxidant enzymes (SOD and GSH-Px) in smoker's saliva might be useful for estimating the level of oxidative stress caused by cigarette smoke. Thus, it may help in patient's education regarding the ill-effects of smoking and determining the evolution and progress of various oral diseases.

Keywords: Antioxidant enzymes, SOD, GSH-Px, Cigarette smokers, Cigarette nonsmokers, Saliva.
How to cite this article: Saggu TK, Masthan KMK, Dudanakar MP, Nisa SUI, Patil S. Evaluation of Salivary Antioxidant Enzymes among Smokers and Nonsmokers. World J Dent 2012;3(1):18-21.

\section{Source of support: $\mathrm{Ni}$}

Conflict of interest: None declared

\section{INTRODUCTION}

Cigarette smoking is well known to be a major cause of various health disorders. It contains many toxic components, such as carbon monoxide, hydrogen cyanide, benzopyrene and oxygen radicals. ${ }^{1,2}$ These components can predispose to different systemic disorders, such as cardiac diseases, cancers, precancerous lesions and pulmonary disorders. ${ }^{3-7}$

Their levels depend on the balance between their rates of production and their rates of clearance by the endogenous antioxidant systems, including superoxide dismutase (SOD), catalase, the glutathione redox cycling enzymes, glutathione peroxidase (GSH-Px) and reductase (GRd) and glutathione itself. $^{8}$

One of the principal reactive oxygen species produced in aerobic organisms is $\mathrm{O}_{2}^{-}$, which is highly cytotoxic. With the cytotoxicity of this oxidant, exposure to cigarette smoke results in increased levels of antioxidant enzymes, such as catalase (CAT), copper/zinc superoxide-dismutase $(\mathrm{Cu} / \mathrm{Zn}$ $\mathrm{SOD})$, peroxidase (POx) and glutathione peroxidase

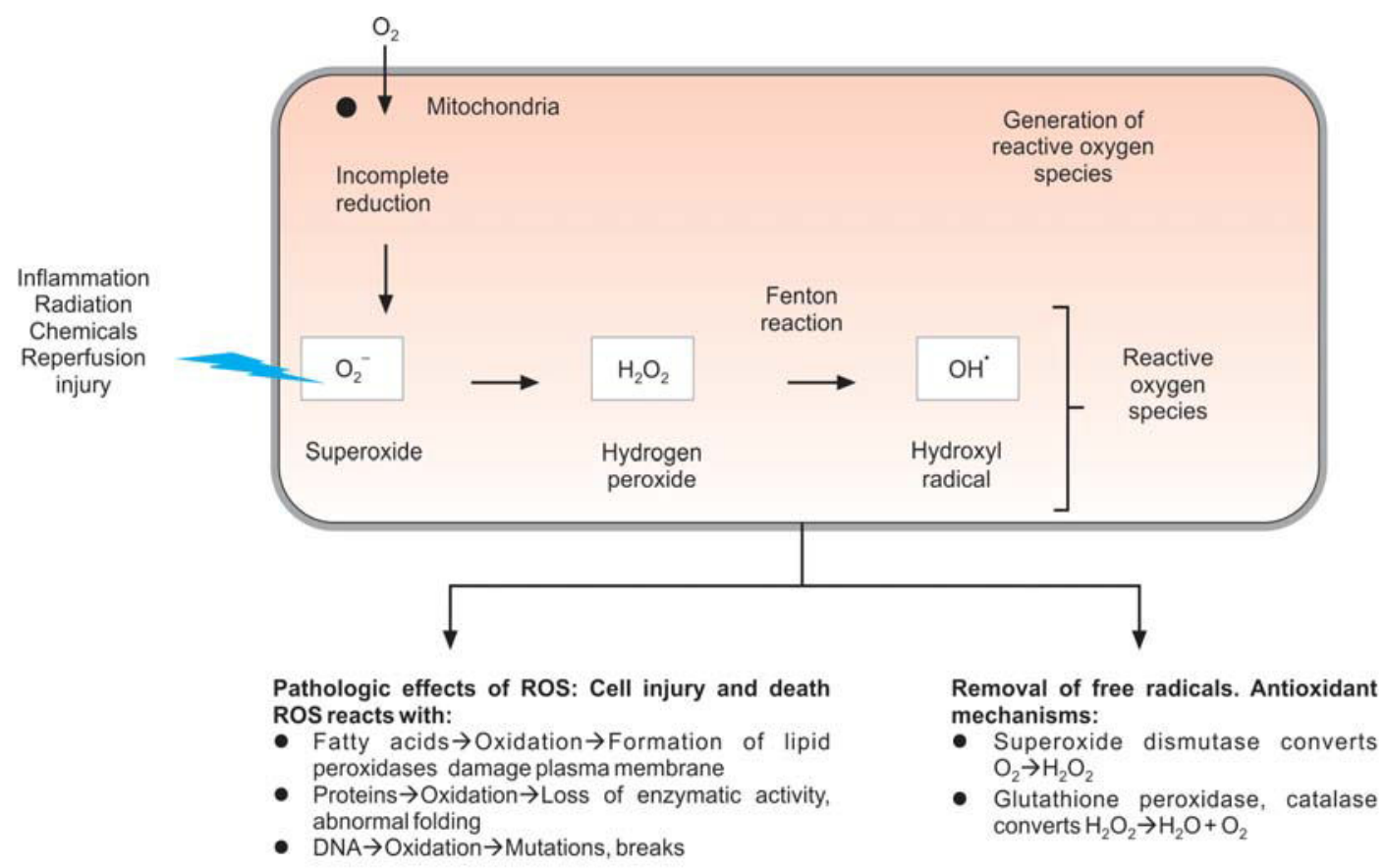

Fig. 1: Diagrammatic representation of production of free radicals, their effects and removal by antioxidant enzymes 
(GSH-Px). ${ }^{9}$ The higher reactive $\mathrm{O}_{2}$ is converted to $\mathrm{H}_{2} \mathrm{O}_{2}$ by SOD. CAT, POx or GSH-Px can in turn convert $\mathrm{H}_{2} \mathrm{O}_{2}$ to molecular oxygen and water (Fig. 1). ${ }^{10,11}$

Under physiologic conditions, these systems tend to maintain a stable state called redox homeostasis. ${ }^{12}$ The imbalance between the formation of free oxygen radicals and inactivation of these species by antioxidant is capable of causing damage to various cellular and extracellular constituents. $^{13}$

Saliva is the first body fluid to encounter cigarette smoke. ${ }^{14}$ The salivary antioxidant system plays a very important role in the anticarcinogenic capacity of saliva and includes various enzymes and molecules, such as uric acid and peroxidase system. ${ }^{14}$

Therefore, in the present study, the effect of smoking on the salivary SOD and GSH levels were measured and compared with that of the nonsmokers.

\section{MATERIALS AND METHODS}

\section{Subjects}

Unstimulated saliva samples were collected from 200 male patients (aged 20-60 years) who were visited to Sree Balaji Dental College and Hospital, Chennai, for routine dental check-up. Among these patients, 100 were smokers (smoking more than 10 cigarettes per day since 5 years) and the remaining 100 were nonsmokers (who had never smoked cigarette). All the participants were informed about the nature of study. All the subjects were healthy without any previous history of systemic disease.

\section{Collection of Saliva}

The participants were asked not to eat or drink 2 hours prior to saliva collection. The smokers were also prohibited from smoking for 1 hour prior to sample collection. Sampling was performed in a quiet room between 9 am and $12 \mathrm{pm}$ to prevent any variations which may be attributable to the circadian rhythm. The participants were instructed to rinse the mouth using distilled water. The unstimulated saliva was collected for atleast 5 minutes in a container and kept at low temperature. Following saliva collection, the samples were centrifuged to remove cell debris for 5 minutes at 2000 to $2500 \mathrm{rpm}$. The supernatant was stored at $4^{\circ} \mathrm{C}$ until tests were performed.

\section{Determination of Antioxidant Enzymes}

The levels of salivary $\mathrm{Cu} / \mathrm{Zn}$ SOD and GSH-Px were measured using standard procedures.

\section{Salivary SOD Analysis}

Superoxide dismutase was assayed by the method of Misra and Fridovich (1972). The collected saliva was diluted with water. Around 0.25 volume of chilled ethanol and 0.15 volume of ice-cold chloroform were added. The mixture was shaken well for a minute at $4{ }^{\circ} \mathrm{C}$ and then centrifuged. The supernatant was taken for the enzyme assay. Tube containing $0.5 \mathrm{ml}$ of the carbonate buffer and $0.5 \mathrm{ml}$ of the EDTA solution, 0.5 of enzyme was added. Their final volume was made to $2.5 \mathrm{ml}$ with distilled water and the reaction was initiated by the addition of $0.2 \mathrm{ml}$ of epinephrine and the increase in absorbance at $480 \mathrm{~nm}$ was measured in a spectrophotometer.

\section{Salivary GSH-Px Analysis}

Glutathione peroxidase was assayed by the method of Rotruck et al (1973). Around $0.2 \mathrm{ml}$ each of EDTA, sodium azide, glutathione and hydrogen peroxide together with suitable volume of buffer and enzyme were mixed together to give a final concentration of $0.08 \mathrm{mM}, 1.0 \mathrm{mM}, 0.4 \mathrm{mM}$, $0.25 \mathrm{mM}$ and $0.08 \mathrm{mM}$ respectively in a total incubation volume of $2 \mathrm{ml}$. Incubation was carried at $37^{\circ} \mathrm{C}$ and the reaction was terminated at 1 minute intervals by the addition of 5\% TCA. A 'zero time' was also carried out simultaneously by addition of TCA prior to the enzyme. To determine the residual glutathione content, the contents were centrifuged and to $2 \mathrm{ml}$ of the supernatant added $8 \mathrm{ml}$ of phosphate solution followed by $1 \mathrm{ml}$ of DTNB and read immediately at $412 \mathrm{~nm}$ in a spectrophotometer.

\section{Statistical Analysis}

The mean values of SOD and GSH-Px between the saliva of smokers and nonsmokers were analyzed using the Student t-test. The data were processed using the statistical package SPSS version 15.0. A probability value of $\mathrm{p}<0.05$ was set as statistically significant.

\section{RESULTS}

The mean levels of salivary SOD were significantly higher $(<0.001)$ in the smoking group than in the nonsmoking

\begin{tabular}{llllll}
\multicolumn{6}{c}{ Table 1: Mean level of SOD enzyme in saliva from smokers } \\
and nonsmokers \\
\hline & Group & $N$ & Mean & $\begin{array}{l}\text { Std. } \\
\text { deviation }\end{array}$ & $p$-value \\
\hline SOD & $\begin{array}{l}\text { Nonsmoker } \\
\text { Smoker }\end{array}$ & 100 & 77.2050 & 4.84625 & $<0.001^{*}$ \\
& 100 & 171.5220 & 11.58909 & \\
\hline
\end{tabular}

*p-value (< 0.001): Highly significant; SOD: superoxide dismutase

Table 2: Mean level of GSH-Px enzyme in saliva from smokers and nonsmokers

\begin{tabular}{llllll}
\hline Group & $N$ & Mean & $\begin{array}{l}\text { Std. } \\
\text { deviation }\end{array}$ & $p$-value \\
\hline GSH-Px & Nonsmoker & 100 & 2.7180 & 0.52960 & $<0.001^{*}$ \\
& Smoker & 100 & 1.5610 & 0.39642 & \\
\hline
\end{tabular}

*p-value (< 0.001): Highly significant; GSH-Px: Glutathione peroxidase 


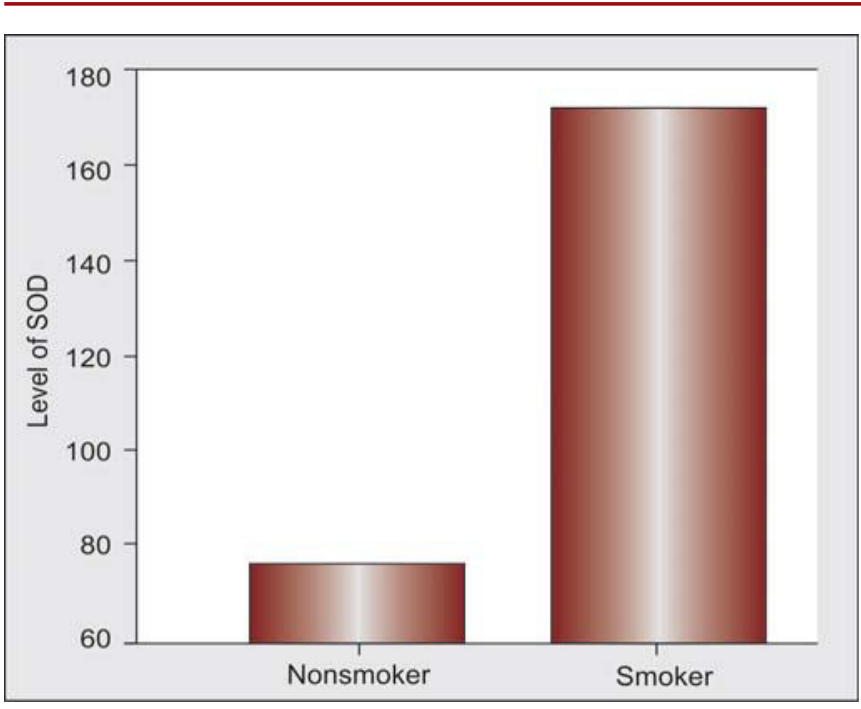

Graph 1: Mean level of SOD enzyme in saliva from smokers and nonsmokers

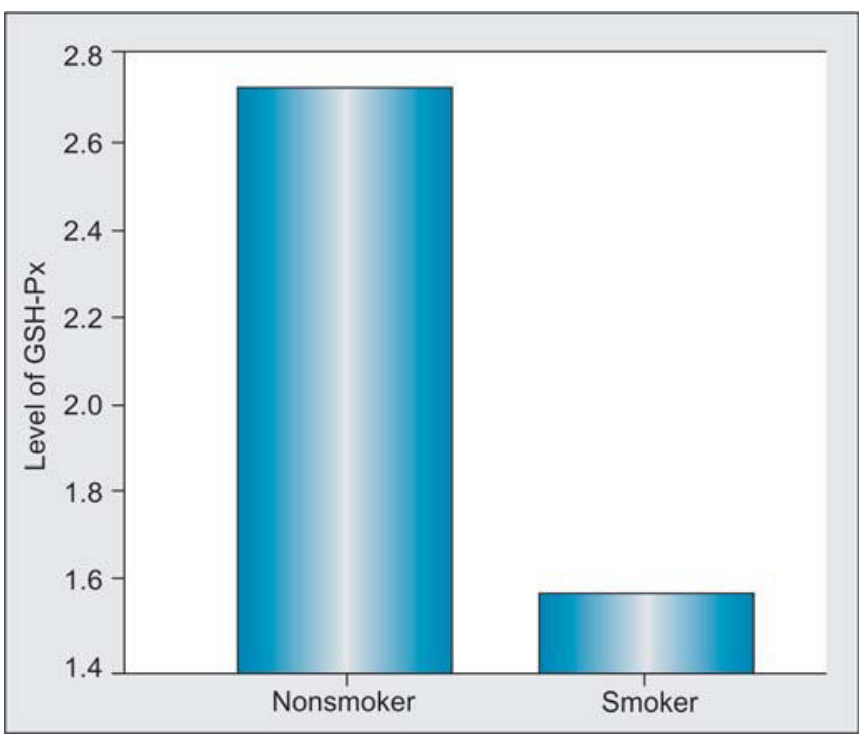

Graph 2: Mean level of GSH-Px enzyme in saliva from smokers and nonsmokers

group is shown in Table 1 and Graph 1, whereas the specific activity levels of GSH-Px was significantly higher $(<0.001)$ in the nonsmoking group than in the smoking group shown in Table 2 and Graph 2.

\section{DISCUSSION}

Oxidative stress status may lead to large number of diseases, including precancerous and neoplastic lesions of the oral cavity which may be due to the altered levels of salivary antioxidant system that fails to cope with the altered level of oxidative stresses originating due to cigarette smoke. The main objective of our study was to measure the activity of antioxidant enzymes in the saliva of smokers and nonsmokers.

The results of our study showed that the mean levels of SOD were significantly higher in the saliva of smokers than nonsmokers. The present study is consistent with the results of previous studies. ${ }^{3,15,16}$ The elevated levels show the defensive system of the body occurring to reduce the free radicals produced by cigarette.

GSH-Px acts as a powerful antioxidant defense system in our body, which converts $\mathrm{H}_{2} \mathrm{O}_{2}$ produced by SOD into nonharmful molecular oxygen and water. ${ }^{3}$ Our results indicate that exposure to cigarette smoke caused a statistically significant decrease in the levels of GSH-Px in the saliva of smokers than nonsmokers. These findings were supported by various previous studies. ${ }^{3,17,18} \mathrm{We}$ found out that the cigarette smoke may alter the detoxification of hydrogen peroxide through a decrease of GSH-Px activity. ${ }^{17}$ The overproduction of $\mathrm{H}_{2} \mathrm{O}_{2}$ may leads to increase consumption of reduced glutathione and thus sufficient amount of reduced glutathione may not be available for the detoxification of $\mathrm{H}_{2} \mathrm{O}_{2}$ leading to elevated oxidative stresses that is involved in a large number of diseases, including precancerous and neoplastic lesions of the oral cavity. 3,17

The altered levels of antioxidant enzymes may have a consistent role in the mechanism by which the toxic effects of cigarette smoke initiate oral inflammatory diseases, promote precancerous transformation and destroy the oral cavity homeostasis. ${ }^{18}$

\section{CONCLUSION}

Measurement of antioxidant enzymes in human saliva might be useful for estimating the level of oxidative stress caused by cigarette smoke.

The purpose of the current study was to measure the antioxidant levels of the saliva in smokers and nonsmoker patients. This analysis may well be of great importance for further understanding the relation between saliva and free radicals. Therefore, more research aimed at examining the altered levels of salivary antioxidants profile in smokers should be considered.

\section{REFERENCES}

1. Raveendran M, Senthil D, Utama B. Cigarette suppresses the expression of $\mathrm{P} 4 \mathrm{H}$ alpha and vascular collagen production. Biochem Biophys Res Commun 2004;323:592-98.

2. Church DF, Pryor WA. Free-radical chemistry of cigarette smoke and its toxicological implications. Environ Health Perspect 1985;64:111-26.

3. Kanehira T, Shibata K, Kashiwazaki H, et al. Comparison of antioxidant enzymes in saliva of elderly smokers and nonsmokers. Gerodontology 2006;23:38-42.

4. Franco EL, Kowalski LP, Oliveria BV. Risk factors for oral cancer in Brazil: A case-control study. Int J Cancer 1989;43: 992-1000.

5. Michael Pittilo R. Cigarettes smoking, endothelial injury and cardiovascular disease. Int J Exp Pathol 2000;81:219-30.

6. Phillips DH. Smoking-related DNA and protein adducts in human tissues. Carcinogenesis 2005;23:1979-2004. 
7. Dwyer TM. Cigarette smoke-induced airway inflammation as sampled by the expired breath condensate. Am J Med Sci 2003;326:174-78.

8. Halliwell B, Gutteridge JMC. Free radicals in biology and medicine (2nd edn). Oxford, UK: Clarendon, 1989.

9. Gilks CB, Price K, Wright JL, et al. Antioxidant gene expression in rat lung after exposure to cigarette smoke. Am J Pathol 1998;152:269.

10. Farmand F, Ehdaie A, Roberts CK, et al. Lead-induced dysregulation of superoxide dismutase, catalase, glutathione peroxidase, and guanylate cyclase. Environ Res 2005;98: 33-39.

11. Kumar, Abbas, Fausto, Mitchell. Robbins-Basic pathology. 8th edition.

12. Droge W. Free radicals in the physiological control of cell function. Physiol Rev 2002;82:47-95.

13. Sies H. Oxidative stress: Oxidants and antioxidants. Academic Press, New York 1991.

14. Greabu M, Battino M, Totan A, et al. Effect of gas phase and particulate phase of cigarette smoke on salivary antioxidants. What can be the role of vitamin $\mathrm{C}$ and pyridoxine? Pharmacol Rep 2007;59:613-18.

15. Baharvand M, Maghami AG, et al. Comparison of superoxide dismutase activity in saliva of smokers and nonsmokers. Southern Medical Journal May 2010;103(5).

16. Nagler RM, et al. Altered salivary profile in heavy smokers and its possible connection to oral cancer. Int Journal of Biological Markers 2007;22:274-80.

17. Giuca MR, Giuggioli E, et al. Effects of cigarette smoke on salivary superoxide dismutase and glutathione peroxidase activity. J Biol Regul Homeost Agents Jul-Sep 2010;24(3): 359-66.
18. Greabu M, Totan A, Battino M, et al. Cigarette smoke effect on total salivary antioxidant capacity, salivary glutathione peroxidase and gamma-glutamyl transferase activity. Biofactors 2008;33(2):129-36.

\section{ABOUT THE AUTHORS}

\section{Tajinder Kaur Saggu (Corresponding Author)}

Senior Lecturer, Department of Oral Pathology and Microbiology Dasmesh Institute of Research and Dental Sciences, Faridkot, Punjab India, e-mail: dr.tajinder_08@yahoo.com

\section{KMK Masthan}

Professor and Head, Department of Oral Pathology and Microbiology Sree Balaji Dental College and Hospital, Chennai, Tamil Nadu, India

\section{Mahesh Pundaleek Dudanakar}

Assistant Professor, Department of Oral Pathology and Microbiology Vasantdada Patil Dental College and Hospital, Sangli, Maharashtra India

\section{Shams UI Nisa}

Assistant Professor, Department of Oral Medicine and Radiology Bharati Vidyapeeth Deemed University Dental College and Hospital Pune, Maharashtra, India

\section{Shankargouda Patil}

Senior Lecturer, Department of Oral Pathology and Microbiology KLE Society's Institute of Dental Sciences, Bengaluru, Karnataka India 